\title{
Volatility, Global Proxy Index, V-A-R: Empirical Study on Pakistan And China Stock Exchanges
}

\author{
Muhammad Arslan', Wajid Shakeel Ahmed ${ }^{2}$, Mansoor Akhter ${ }^{3}$ \\ ${ }^{1}$ Faculty of Management Sciences, Capital University of Science and Technology, Islamabad, Pakistan \\ ${ }^{2}$ Department Faculty of Management Sciences, COMSATS Institute of Information Technology, Islamabad \\ ${ }^{3}$ University Institute of Management Sciences, PMAS-Arid Agriculture University, Rawalpindi, Pakistan
}



\section{INTRODUCTION}

Generally, risk is defined as a probability of loss due to unexpected changes in financial market and has been widely interpreted with in specific context. Piroozfar [1] describe differrent types of financial risk in his study as Equity risk, Exchange rate risk, Interest rate risk, Commodity risk, and Liquidity risk. Korner, K.F., Kneafsey, K.P., \& Claessens [2] and Mark R. Manfredo and Raymond M. Leuthold [3] used models to meausre the volatility in comodity market and found that the commodity risk stems from the change in future income level and market volatility. DZ BANK [4] define equity risk under its annual report as a risk of loss due to negative change in value of stocks. Risk measurement considered as an essential part of financial manager's job in every era. Different tools have been used to analyze and measure the risk at different levels. These risk measurement tools enable the financial managers to identify expected risk, generate best possible mechanism, implementing and tracking risk. Due to globalization and more advancement if finance sector, stock markets all around the world are more aligned and effected with the movement in country specific and other economic level risks.

In 1960's Fama gives efficient market hypothesis (EMH) that describes the informational efficiency of financial market. Efficient market presents the true value of securities. Efficient capital market refers to rapidly adjustment of prices in response to new information. Fama's efficient market 
theory describes that it might be a situation that investor is assured that price of security is fully consistent with all the information in market. Fama and Schwert [5] further categorize efficient market hypothesis in three different levels starting form weak-form efficient market to semi-strong-form and semi-strong form to strong-form efficient market level of hypothesis. This study posits that the investment opportunities are closely connected to the stock exchanges across the globe so they possess the greater sensitivity towards the efficiency level of these markets.

Changes in returns are due to variations that exist in the markets and the common measure to capture these movements is the standard deviation. These variations are connected to the sources of risk out of which the most important source is the volatility. Sudden changes in seurities prices due to any reason in stock market is reffered as stock market volatility [6]. Values of highly volatile instruments suffer with higher probability of increase or decrease in end values. Unexpected changes, either due to negative or positive in prices of instrument, will a bit of concern for the stakeholders expectations.

The traditional methods which are typically used to estimate and measure the volatility are standard deviation or variance that are unconditional and cannot capture the characteristics of financial time-series data [7]. For that one of the accepted model for the estimation and measurement of volatility is Generalized Autoregressive Conditional Heteroskedasticity (GARCH) [7]. It has been extracted from the initial system, to gauge volatility for financial series, as proposed by Engle [8] known as Autoregressive Conditional Heteroskedasticity (ARCH) system. Under this the said series of data posit the variations tend to be greater at some points compared to others which is caused by heteroskedasticity phenomenon. Instead of treating the risk as a linear trend, ARCH/GARCH treats it as a variance in the model, by relaxing the normality condition (Engle, 2001). Another study showed that the scholars used standard error of empirical quantile estimate by using monte carlo simulation [9].

This GARCH $(1,1)$ model as a non-parametric model consider negative and positive error terms to have symmetric effects on volatility, i.e. that negative and positive shocks have the same effect on volatility [10]. A general understanding is that negative returns tend to be followed by periods of greater volatility than positive returns of equal size. Similarly, the bad news as compared to good news, tend to increase more volatility [11]. An explanation of the asymmetric response of return volatility to the sign of the shock is that positive and negative shocks lead to different values of a firm financial leverage, which in turn will result in different volatilities [10]. In order to capture the asymmetry in return volatility, the non-parametric model approach is an appropriate tool to investigate the resulted effect of volatility phenomenon.

\section{RESEARCH METHODOLOGY}

This study firstly use normal $\log -\operatorname{GARCH}(1,1)$ and ARMA-GARCH$(1,1)$ models i.e moving average model, for the computation of value at $\operatorname{risk}(\mathrm{V}-\mathrm{a}-\mathrm{R})$ at $5 \%$ level. This methodolgy includes the adjustments of previous historical data on markets under consideration to reveal the significance among market variables and existing volaitlity of the market as proposed by (White, 1998). Also, the author used filter historical simulation in in his paper for the computation of V-a-R to measure the volatility in order to meet up the current challenges, which is align to the past work done by Christoffersen [12].

Let assume that $\mathrm{rt} ; \mathrm{t}=1, \ldots ., \mathrm{T}$ that represent a continuous change in stock prices returns for a specific holding time $t$. if the $\mathrm{v}_{\mathrm{t}}$ is the value/price of stock then $\mathrm{r}_{\mathrm{t}}=\ln \left(\mathrm{v}_{\mathrm{t}}\right)-\ln \left(\mathrm{v}_{\mathrm{t}}\right)$, where $\ln$ is the natural logarithm.

So we can write the model as:

$$
\begin{aligned}
& \mathrm{r}_{\mathrm{t}+1}=\mathrm{c}+\varnothing 1 \mathrm{r}_{\mathrm{t}}+\varnothing 2 \mathrm{r}_{\mathrm{t}-1}+\ldots+\varnothing \mathrm{kr}_{\mathrm{t}+1-\mathrm{k}}+\check{3} 1 \mathrm{X}_{1, t+1}+\check{\zeta}_{2} \mathrm{X}_{2, t+1}+\ldots . .+\check{\zeta}_{\mathrm{s}} \mathrm{X}_{\mathrm{s}, \mathrm{t}+1}+\sigma_{\mathrm{t}+1} \mathrm{~S}_{\mathrm{t}+1} ;
\end{aligned}
$$

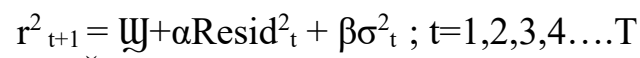

where resid $\mathrm{t}_{\mathrm{t}}=\left(\mathrm{r}_{\mathrm{t}}-\mathrm{c}-\Sigma \varnothing_{\mathrm{i}} \mathrm{r}_{\mathrm{t}-1}-\Sigma \check{\zeta}_{\mathrm{j}} \mathrm{x}_{\mathrm{j}, \mathrm{t}}\right) ; \boldsymbol{\varsigma}_{\mathrm{t}}$ present the white noise with mean and variance of zero and internal factors that influence the $r_{t}$ are the $\alpha+\beta<1, X_{1 \ldots . . .} X_{s .}$

Another model has been used in this study is known as moving average model i.e. ARMA$\operatorname{GARCH}(1,1)$ model and can be expressed as under: 
Where;

$$
\mathrm{X}_{\mathrm{t}}=\mathrm{c}+\varepsilon_{\mathrm{t}}+\sum_{i=1}^{q} \wp_{\mathrm{i}} \mathrm{X}_{\mathrm{t}-1}+\sum_{i=1}^{q} \sigma_{\mathrm{i}}+\varepsilon_{\mathrm{t}-\mathrm{i}}
$$

$\mathrm{C}$ is constant, $\wp$ is parameters used in AR and $\sigma$ are the parameters used in MA while $\varepsilon_{\mathrm{t}}$ refer as the white noise error term.

Jorion [6] mentioned different types of methods for risk managers to estimate the possible financial risk out of which $\mathrm{V}-\mathrm{a}-\mathrm{R}$ is known as an advanced model to estimate the volatility factoe. $\mathrm{V}$-a-R method explained the max possible risk at any certain day at time period $t$. we generally quote the value or percentage with confidence level of $10 \%, 05 \%$ and $01 \%$. In case of extremely positive or negative returns $\mathrm{V}-\mathrm{a}-\mathrm{R}$ computed on normal distribution will gave vague values. The $100 \alpha \%$ one day ahead $V-a-R(\lambda \alpha, t)$ is defined as;

$$
\mathrm{P}\left[\mathrm{r}_{\mathrm{t}}<=\lambda_{\alpha, \mathrm{t}} \mid \mathrm{r}_{\mathrm{t}}-1\right]=\alpha
$$

Assumptions on which V-a-R Model is calculated do not change over the specific holding time period. These assumptions are only applicable for the short holding time period. Historical simulation is commonly used non-parametric tool. Filtered Historical Simulation is considering the more appropriate and accurate predictor of risk then the other Risk assessment models.Calculation of $\mathrm{V}-\mathrm{a}-\mathrm{R}$ is quite simple using filtered historical simulation through given formula;

$$
\mathrm{V}-\mathrm{a}-\mathrm{R}=\mathrm{CI} \times \mathrm{Z}_{\alpha} \sqrt{h \mathrm{t}}
$$

Where CI is the value of cash invested in capital market, $\mathrm{Z}_{\alpha}$ is the value normal distribution and $\mathrm{h}_{\mathrm{t}}$ is the conditional variance of $r$ returns series.

Inorder to determine which model is best fit out of some the 'akaike information criteria' (AIC) and 'schwarz information critria' (SIC) is the best choice [13]. Here the V-a-R @ 95\% level of confidence has been incorporated on two models i.e. $\log \operatorname{GARCH}(1,1)$ and ARMA-GARCH$(1,1)$ respectively. Therefore, dispersion resulted from the V-a-R estimation@ @ 5\% significant level based upon two models, such as;

$$
\begin{aligned}
& \Omega_{\mathrm{A}}=\sum\left(\mathrm{r}_{\mathrm{t}}-\mathrm{V}-\mathrm{a}-\mathrm{R}_{\mathrm{At}, \alpha}\right)^{2} \\
& \Omega_{\mathrm{B}}=\sum\left(\mathrm{r}_{\mathrm{t}}-\mathrm{V}-\mathrm{a}-\mathrm{R}_{\mathrm{Bt}, \alpha}\right)^{2}
\end{aligned}
$$

Where as, $\Omega_{\mathrm{A}}$, represents a $\log$ normal model; $\Omega_{\mathrm{B}}$, represents a ARMA model; $\mathrm{r}_{\mathrm{t}}$, represents the log normal returns for respective series; $\alpha$, represents confidence interval level of $5 \%$.

\section{RESULTS AND FINDINGS}

\subsection{Quantitative Model Analysis}

Pakistan-China Stock Markets. The standard procedure recommended using the non-parametric models like $(\mathrm{ARCH}) / \mathrm{GARCH}(1,1)$ is to run the test of ARCH LM test statistics. This test postulates that if the p-value is insignificant after running the regression model then there is no heteroskedasticity condition existed in the proposed model and hence no non-parametric model should be used and vice versa. Estimated results given in Tables 1-4 have shown that the existence of ARCH effect in both the regression equations with respect to Pakistan and China perspective. Thus, the results have confirmed the existence of volatility in both the countries' stock exchanges and hence cannot be tested by using parametric models.

Log-GARCH $(\mathbf{1}, \mathbf{1})$ - Model 1. The below Table 1 shows the model $\log$-GARCH $(1,1)$ after keeping returns of Shanghai Stock exchange as an exogenous variable in the quantitative model equation. By looking at the $p$ values of the global proxy index such as gold (R_GOLD), returns of oil (R_OIL) and returns of YUAN (R_YUAN), there found to be an insignificant impact over all.

Table 1. Log GARCH $(1,1)$ test (R_PSE Constant)

\begin{tabular}{crrrr}
\hline \hline Variable & Coefficient & Std. Error & z-Statistic & Prob. \\
\hline \hline C & 0.001158 & 0.000157 & 7.388800 & 0.0000 \\
R_GOLD & -0.015157 & 0.013400 & -1.131108 & 0.2580 \\
R_OIL & 0.006928 & 0.006238 & 1.110547 & 0.2668
\end{tabular}

Volatility, Global Proxy Index, V-A-R: Empirical Study on Pakistan and China Stock (Muhammad Arslan) 


\begin{tabular}{ccccr} 
R_PKR & -0.105976 & 0.074299 & -1.426354 & 0.1538 \\
R_YUAN & -0.174633 & 0.206185 & -0.846973 & 0.3970 \\
\hline \hline \multicolumn{6}{c}{ Variance Equation } & & \\
\hline \hline C & $6.90 \mathrm{E}-06$ & $4.17 \mathrm{E}-07$ & 16.53928 & 0.0000 \\
RESID(-1)^2 & 0.161138 & 0.009493 & 16.97362 & 0.0000 \\
GARCH(-1) & 0.804246 & 0.008748 & 91.93550 & 0.0000 \\
R_SSE & $9.42 \mathrm{E}-05$ & $3.09 \mathrm{E}-05$ & 3.047699 & 0.0023 \\
\hline \hline
\end{tabular}

However, the variable i.e. R_SEE representing the Shanghai composite index returns have shown significant impact on KSE-100 index. The variance equation has shown that ARCH and GARCH terms are significant too, with the p-value below $1 \%$.

The below Table 2 shows the model $\log$-GARCH $(1,1)$ after keeping returns of Karachi Stock exchange as an exogenous variable in the quantitative model equation. By looking at the $p$ values of the global proxy index such as gold (R_GOLD), returns of oil (R_OIL) and returns of YUAN (R YUAN), there found to be a significant impact over all. However, the variable i.e. R PSE representing the Karachi -100 index returns have shown an insignificant impact on Shanghai composite index. The variance equation has shown that $\mathrm{ARCH}$ and $\mathrm{GARCH}$ terms are significant too, with the p-value below $1 \%$ as shown in the table below.

Table 2. Log GARCH $(1,1)$ test (R_SSE Constant)

\begin{tabular}{ccccc}
\hline \hline Variable & Coefficient & Std. Error & Z-Statistic & Prob. \\
\hline \hline C & 0.000184 & 0.000182 & 1.011114 & 0.3120 \\
R_GOLD & 0.069258 & 0.018629 & 3.717752 & 0.0002 \\
R_OIL & 0.023397 & 0.008219 & 2.846693 & 0.0044 \\
R_PKR & -0.048397 & 0.067505 & -0.716935 & 0.4734 \\
R_YUAN & -1.001791 & 0.249133 & -4.021112 & 0.0001 \\
\hline \hline RESID $(-1)^{\wedge} 2$ & Variance Equation & & & \\
GARCH(-1) & $2.36 \mathrm{E}-06$ & $2.84 \mathrm{E}-07$ & 8.307491 & 0.0000 \\
R_PSE & 0.060618 & 0.003106 & 19.51520 & 0.0000 \\
& 0.931347 & 0.002945 & 316.2978 & 0.0000 \\
\hline \hline & $-8.71 \mathrm{E}-05$ & $5.42 \mathrm{E}-05$ & -1.607607 & 0.1079 \\
\hline \hline
\end{tabular}

ARMA-GARCH $(\mathbf{1}, \mathbf{1})$ - Model 2. Auto regressive Moving Average (ARMA) is the second model to quantify the shocks in existing data. It uses AR (auto regressive) dynamic model with MA (moving Average) term. Estimated results of Inverted AR Roots and inverted MA Roots are respectively 0.85 and 0.80 are less than the criteria of 1 . It is evident from the p-value that 2 autoregressive and 2 moving average terms incorporated in the model are statistically significant at $1 \%$ level of confidence in a mean equation as per Table 3. In a variance equation the ARCH and GARCH terms along with the exogenous variable R_SSE. This shows that the volatility in Shanghai stock exchange influenced the Pakistan stock exchange.

Table 3. ARMA-GARCH $(1,1)$ test (R_PSE Constant)

\begin{tabular}{crrrr}
\hline \hline Variable & Coefficient & Std. Error & z-Statistic & Prob. \\
\hline \hline C & 0.001124 & 0.000208 & 5.397326 & 0.0000 \\
AR(1) & 1.462677 & 0.099058 & 14.76591 & 0.0000 \\
AR(2) & -0.520028 & 0.099402 & -5.231586 & 0.0000 \\
MA(1) & -1.381190 & 0.099284 & -13.91155 & 0.0000 \\
MA(2) & 0.429424 & 0.095076 & 4.516647 & 0.0000 \\
MA(3) & 0.028503 & 0.019528 & 1.459605 & 0.1444
\end{tabular}




\begin{tabular}{|c|c|c|c|c|}
\hline \multicolumn{5}{|c|}{ Variance Equation } \\
\hline $\mathrm{C}$ & $7.08 \mathrm{E}-06$ & 4.19E-07 & 16.90076 & 0.0000 \\
\hline $\operatorname{RESID}(-1)^{\wedge} 2$ & 0.166294 & 0.009951 & 16.71152 & 0.0000 \\
\hline GARCH(-1) & 0.798617 & 0.009126 & 87.50554 & 0.0000 \\
\hline R_SSE & $9.23 \mathrm{E}-05$ & $3.13 \mathrm{E}-05$ & 2.954249 & 0.0031 \\
\hline
\end{tabular}

Similarly, the ARMA-GARCH $(1,1)$ model applied in context of Shanghai stock market showed that the significant $p$ values at $1 \%$ achieved by 1 autoregressive and 1 moving average term in a mean equation. Also, in the variance equation, both $\mathrm{ARCH}$ and $\mathrm{GARCH}$ terms are statistically significant as evident by the $p$ values in Table 4. Interesting findings has reported by the variable R_PSE i.e. an exogenous variable that has shown insignificant impact on the volatility of Shanghai Stock exchange. However, the ARCH and GARCH terms are statistically significance showing that the model fully explains the magnitude of volatility and shocks observed in the Shanghai stock exchange.

Table 4. ARMA GARCH $(1,1)$ test (R_SSE Constant)

\begin{tabular}{ccccc}
\hline \hline Variable & Coefficient & Std. Error & z-Statistic & Prob. \\
\hline \hline C & 0.000380 & 0.000213 & 1.784720 & 0.0743 \\
AR(1) & -0.031864 & 0.026623 & -1.196867 & 0.2314 \\
AR(2) & 0.952746 & 0.026217 & 36.34042 & 0.0000 \\
MA(1) & 0.049517 & 0.025861 & 1.914746 & 0.0555 \\
MA(2) & -0.948079 & 0.024250 & -39.09571 & 0.0000 \\
MA(3) & -0.011860 & 0.009173 & -1.292909 & 0.1960 \\
\hline \hline & & & & \\
Variance Equation & & & \\
RESID(-1)^2 & & & & \\
GARCH(-1) & $2.65 \mathrm{E}-06$ & $3.26 \mathrm{E}-07$ & 8.119768 & 0.0000 \\
R_PSE & 0.062169 & 0.003587 & 17.33394 & 0.0000 \\
\hline \hline & 0.929935 & 0.003657 & 254.3115 & 0.0000 \\
\hline \hline
\end{tabular}

Global Proxy Index. The analysis has been applied on variables in global proxy index i.e. currency, Oil and Gold variables for both the countries' market. There is no ARCH effect existed in the model of currency of Pakistan and thus cannot run a GARCH $(1,1)$ model to do the further calculations. However, the currency of China in the global proxy index has shown a potential variation to be examined which capacitate our results on the volatility among other indicators in the global proxy index against the respective stock exchanges of both the countries, as per Table 5-6. Also there found to be an $\mathrm{ARCH}$ effect in existed in respective indicators in global proxy index with respect to possible volatility in PSE and SSE indices, as per Table 7-10.

Log-GARCH $(\mathbf{1}, \mathbf{1})$ - Model 1. The below Table 5 shows the model $\log -G A R C H(1,1)$ of R_Yuan, after keeping returns of PSX and SSE as an exogenous variable in the quantitative model equation. By looking at the $\mathrm{p}$ values of other global proxy index such as returns of gold price (R_GOLD), returns of oil (R_OIL) and returns of PKR (R_PKR), there found to be an insignificant impact over all in the mean equation. However, the variable i.e. R_PSE, R_SEE along with the ARCH and GARCH terms in the variance equation have shown significant impact with respective volatility in Yuan.

Table 5. Log GARCH $(1,1)$ test (R_Yuan Constant)

\begin{tabular}{lllll}
\hline \hline Variable & Coefficient & Std. Error & z-Statistic & Prob.
\end{tabular}

Volatility, Global Proxy Index, V-A-R: Empirical Study on Pakistan and China Stock (Muhammad Arslan) 


\begin{tabular}{crrrr}
\hline \hline C & $3.49 \mathrm{E}-05$ & $2.42 \mathrm{E}-05$ & 1.445542 & 0.1483 \\
R_PKR & 0.004399 & 0.011147 & 0.394631 & 0.6931 \\
R_GOLD & 0.000238 & 0.001933 & 0.122918 & 0.9022 \\
R_OIL & -0.001114 & 0.001404 & -0.793445 & 0.4275 \\
\hline \hline \multicolumn{5}{r}{ Variance Equation } \\
\hline \hline C & $5.06 \mathrm{E}-07$ & $7.15 \mathrm{E}-08$ & 7.070353 & 0.0000 \\
RESID(-1)^2 & 0.149917 & 0.025394 & 5.903637 & 0.0000 \\
GARCH(-1) & 0.599958 & 0.054015 & 11.10717 & 0.0000 \\
R_PSE & $-8.90 \mathrm{E}-06$ & $1.52 \mathrm{E}-06$ & -5.846486 & 0.0000 \\
R_SSE & $9.34 \mathrm{E}-06$ & $8.99 \mathrm{E}-07$ & 10.38721 & 0.0000 \\
\hline \hline
\end{tabular}

Similarly, the log-GARCH $(1,1)$ model has been applied to examine the volatility existed in the R_Oil variable in the global proxy index with respective stock exchanges in Table 6. Only one of the variables in the mean equation of the model i.e. R_GOLD has shown the significant impact on the volatility of oil price indicator. In the variance equation the respective $\mathrm{ARCH}$ and GARCH terms are significant at $1 \%$ level showing the credibility of the model. Also, exogenous variables such as R_PSE and R_SSE i.e. the returns of both the exchanges have shown the significant impact too for explaining the possible variations in oil indicator.

Table 6. Log GARCH $(1,1)$ test (R_Oil Constant)

\begin{tabular}{crrrr}
\hline \hline Variable & Coefficient & Std. Error & z-Statistic & Prob. \\
\hline \hline C & 0.000317 & 0.000285 & 1.112178 & 0.2661 \\
R_PKR & -0.092407 & 0.125157 & -0.738325 & 0.4603 \\
R_GOLD & 0.274845 & 0.025792 & 10.65639 & 0.0000 \\
R_YUAN & -0.773896 & 0.352629 & -2.194648 & 0.0282 \\
\hline \hline & \multicolumn{3}{c}{} \\
\hline \hline Variance Equation & & \\
RESID(-1)^2 & $5.30 \mathrm{E}-06$ & $7.94 \mathrm{E}-07$ & 6.669907 & 0.0000 \\
GARCH(-1) & 0.057903 & 0.004533 & 12.77254 & 0.0000 \\
R_PSE & 0.935668 & 0.004957 & 188.7476 & 0.0000 \\
R_SSE & -0.000727 & 0.000136 & -5.362111 & 0.0000 \\
\hline \hline
\end{tabular}

The volatility of a final indicator in the global proxy index i.e. Gold price has been examined through the log-GARCH $(1,1)$ against the variations exists in both the stock exchanges. The Table 7 has reported the two separate equations i.e. mean and variance. The former one showed that only the oil price indicator in global proxy index has shown the significant association in explaining the volatility existed in R_Gold at $1 \%$ confidence of interval. Whereas, in the variance equations except the R_PSE, all the variables have shown significant impact in explaining the volatility in R_Gold.

Table 7. Log GARCH $(1,1)$ test (R_Gold Constant)

\begin{tabular}{crrrr}
\hline \hline Variable & Coefficient & Std. Error & z-Statistic & Prob. \\
\hline \hline C & 0.000317 & 0.000147 & 2.152191 & 0.0314 \\
R_OIL & 0.046741 & 0.006610 & 7.071059 & 0.0000 \\
R_PKR & -0.084581 & 0.084963 & -0.995510 & 0.3195 \\
R_YUAN & 0.167018 & 0.125036 & 1.335759 & 0.1816 \\
\hline \hline & Variance Equation & \\
\hline \hline
\end{tabular}




\begin{tabular}{crrrr} 
C & $1.98 \mathrm{E}-06$ & $1.75 \mathrm{E}-07$ & 11.33948 & 0.0000 \\
$\mathrm{RESID}(-1)^{\wedge} 2$ & 0.046759 & 0.002959 & 15.79993 & 0.0000 \\
GARCH(-1) & 0.937004 & 0.003532 & 265.2785 & 0.0000 \\
R_PSE & $-2.22 \mathrm{E}-05$ & $2.76 \mathrm{E}-05$ & -0.804945 & 0.4209 \\
R_SSE & -0.000101 & $2.11 \mathrm{E}-05$ & -4.772200 & 0.0000 \\
\hline
\end{tabular}

ARMA-GARCH $(\mathbf{1}, \mathbf{1})$ - Model 2. Auto regressive Moving Average (ARMA) is the second model to quantify the shocks in existing data of global proxy index. The Table 8 showed the results in favor of using this model with respect to the variance equation. All the ARCH and GARCH terms along with the exogenous variables i.e. R_PSE and R_SSE are statistically significant at the $1 \%$ level.

Table 8. ARMA GARCH $(1,1)$ test (R_Yuan Constant)

\begin{tabular}{crrrr}
\hline \hline Variable & Coefficient & Std. Error & z-Statistic & Prob. \\
\hline \hline C & $-4.43 \mathrm{E}-05$ & $3.60 \mathrm{E}-05$ & -1.231426 & 0.2182 \\
AR(1) & 0.005000 & 19.59835 & 0.000255 & 0.9998 \\
AR(2) & 0.005000 & 8.920245 & 0.000561 & 0.9996 \\
MA(1) & 0.005000 & 19.59342 & 0.000255 & 0.9998 \\
MA(2) & 0.005000 & 8.744126 & 0.000572 & 0.9995 \\
MA(3) & 0.005000 & 0.136431 & 0.036649 & 0.9708 \\
\hline \hline Cariance Equation & & \\
RESID(-1) 2 & $6.09 \mathrm{E}-07$ & $9.60 \mathrm{E}-08$ & 6.342121 & 0.0000 \\
GARCH(-1) & 0.149999 & 0.030367 & 4.939492 & 0.0000 \\
R_PSE & 0.599997 & 0.059570 & 10.07208 & 0.0000 \\
R_SSE & $-1.60 \mathrm{E}-05$ & $1.77 \mathrm{E}-06$ & -9.058904 & 0.0000 \\
\hline \hline & $4.21 \mathrm{E}-06$ & $9.86 \mathrm{E}-07$ & 4.274289 & 0.0000 \\
\hline \hline
\end{tabular}

This showed that the existing volatility in R Yuan currency has been affected by both of the stock exchanges. Also, ARMA-GARCH $(1,1)$ model has been applied to examine the volatility existed in the R_Oil variable in the global proxy index with respective stock exchanges in Table 9. Interestingly, all the ARMA terms in the mean and variance equation alike are statistically significant at $1 \%$ level. The moving average terms also have a significant impact on the R_Oil, as a global proxy index. Moreover, the exogenous variables like R_PSE and R_SSE have fully explained the volatility on Oil prices with a significant impact.

Table 9. ARMA GARCH $(1,1)$ test (R_Oil Constant)

\begin{tabular}{ccccc}
\hline \hline Variable & Coefficient & Std. Error & Z-Statistic & Prob. \\
\hline C & 0.000392 & 0.000281 & 1.396397 & 0.1626 \\
AR(1) & 0.567354 & 0.005348 & 106.0906 & 0.0000 \\
AR(2) & -0.990174 & 0.004529 & -218.6127 & 0.0000 \\
MA(1) & -0.602668 & 0.015903 & -37.89565 & 0.0000 \\
MA(2) & 1.010208 & 0.010433 & 96.83240 & 0.0000 \\
MA(3) & -0.036460 & 0.014943 & -2.439832 & 0.0147 \\
\hline \hline Rariance Equation & & \\
RESID(-1) 2 & V.53E-06 & $7.95 \mathrm{E}-07$ & 6.951396 & 0.0000 \\
GARCH(-1) & 0.055555 & 0.004518 & 12.29605 & 0.0000 \\
R_PSE & 0.937736 & 0.004941 & 189.7792 & 0.0000 \\
R_SSE & -0.000824 & 0.000135 & -6.093742 & 0.0000 \\
\hline \hline
\end{tabular}

Similarly, the ARMA-GARCH $(1,1)$ model has been tested on the last indicator in the global proxy index i.e. R_Gold. The Table 10 has shown that results based on the two separate equations i.e. mean

Volatility, Global Proxy Index, V-A-R: Empirical Study on Pakistan and China Stock (Muhammad Arslan) 
and variance equations. In the mean equation all AR dynamic and MA moving average terms have shown significant associations with the R_Gold, except MA(3). In terms of variance equations, ARMA and GARCH along with the R_SSE as an exogenous variable have shown significant associations in explaining the existed volatility in gold prices.

Table 10. ARMA GARCH $(1,1)$ test (R_Gold Constant)

\begin{tabular}{|c|c|c|c|c|}
\hline Variable & Coefficient & Std. Error & z-Statistic & Prob. \\
\hline $\mathrm{C}$ & 0.000326 & 0.000146 & 2.232323 & 0.0256 \\
\hline $\operatorname{AR}(1)$ & 0.656899 & 0.004928 & 133.3063 & 0.0000 \\
\hline $\operatorname{AR}(2)$ & -0.983418 & 0.004762 & -206.4934 & 0.0000 \\
\hline $\mathrm{MA}(1)$ & -0.664528 & 0.017483 & -38.00909 & 0.0000 \\
\hline MA(2) & 0.989812 & 0.012381 & 79.94459 & 0.0000 \\
\hline MA(3) & 0.002770 & 0.017028 & 0.162684 & 0.8708 \\
\hline \multicolumn{5}{|c|}{ Variance Equation } \\
\hline $\mathrm{C}$ & 2.83E-06 & $2.31 \mathrm{E}-07$ & 12.23991 & 0.0000 \\
\hline $\operatorname{RESID}(-1)^{\wedge} 2$ & 0.063011 & 0.003469 & 18.16495 & 0.0000 \\
\hline GARCH(-1) & 0.915017 & 0.004263 & 214.6181 & 0.0000 \\
\hline R_PSE & $5.15 \mathrm{E}-06$ & $2.91 \mathrm{E}-05$ & 0.176971 & 0.8595 \\
\hline R_SSE & $-8.25 \mathrm{E}-05$ & $2.82 \mathrm{E}-05$ & -2.924781 & 0.0034 \\
\hline
\end{tabular}

\subsection{Risk assessment tool - Value at risk (V-a-R)}

Composite period analysis. Given graph below describes the relationship between the $\mathrm{V}-\mathrm{a}-\mathrm{R}$ and the returns of PSX when incorporated the model 1 equation in assessing the magnitude of risk for all data as per Figure 1. The bandwidth comprises of two independent series 1 and 2 i.e. V-a-R $=-1.65 \sqrt{h} \mathrm{t}$ and $\mathrm{V}-\mathrm{a}-\mathrm{R}=1.65 \sqrt{h} \mathrm{t}$ respectively. This arrangement shows the maximum loss with confidence level of $05 \%$ over the observed time period with respect to Karachi stock index. Results evident that year 2000, 2002 and 2008 shows the worst loss scenario for Pakistan capital market. The maximum loss occurs at year 2000 is approximately -0.08 . It followed by the distress situation of year 2007 to 2010, which is evident of possible effects of financial crisis.

There is an indication of market crash in Pakistan stock exchange too, during the year 2008 showed by the little horizontal line. When applied the model 2 equation for assessing the maximum loss incurred in composite period analysis, it is evident that this model has shown the close association with the respective volatility and shocks in PSX.

On the basis of choosing a best model out of two, it is observed that the resulted dispersion out of Pakistan stock exchange price indices is less in the model $2^{\text {nd }}$, compared to the $1^{\text {st }}$ one. The details are based upon the whole data of approximately 15 years and the respective models' values are given as under;

$$
\begin{aligned}
& \Omega_{\mathrm{A}, \mathrm{PSE}}=2.8081 \\
& \Omega_{\mathrm{B}, \mathrm{PSE}}=2.7874
\end{aligned}
$$

The evidence is given in the graph represent by Figure 1, which states the situation for composite years analysis. Clearly the Model $2^{\text {nd }}$ line is above the Model $1^{\text {st }}$ line and the dispersion of returns of price indices of Pakistan stoack exchange move with tendem to respective two models. The graph shows the relation between the bandwidth of V-a-R and the Pakistan stock variations at the $5 \%$ confidence level. The analysis has addressed that there is a similarity exists in both the trends generated by both the models under study.

Figure 1. Calculation of V-a-R on volatility of PSE through Log-GARCH and ARMA-GARCH model 1, 2 



However, the model-2 trend has shown the less values of an average sum of V-a-R compared to model-1 which are 2.787 and 2.808 respectively. The graph describes the relationship between the bandwidth of $\mathrm{V}$-a-R with respective volatility of SSE after incorporated the model 1 equation in assessing the magnitude of risk for all data as per the Figure 2. The bandwidth comprises of two independent series 1 and 2 i.e. $\mathrm{V}-\mathrm{a}-\mathrm{R}=-1.65 \sqrt{h t}$ and $\mathrm{V}-\mathrm{a}-\mathrm{R}=1.65 \sqrt{h t}$ respectively.

This arrangement shows the maximum loss with confidence level of $05 \%$ over the observed time period with respect to Shanghai stock index. Our expected loss in the year 2008 is recorded as -0.06 which is lower compared to PSX in Pakistan. This is time of financial crisis that hits the economy of the World. Moreover, the maximum loss from the trend found to be approximately 0.075 , in the year 2015, showing the greater magnitude of risk caused by the possible shocks evident in Shanghai stock exchange.

The model 2 equation generates the trend similar to the previous model 1 , but with more precision and accuracy. This is evident from the close association among the $\mathrm{V}$-a- $\mathrm{R}$ bandwidth and the volatility of Shanghai stock exchange during the composite period. The possible average sum of variance by $\mathrm{V}-\mathrm{a}-\mathrm{R}$ in the model 2 has reported the value -0.067 compared to -0.06 by model 1 . There is not much of the difference showing that the both the models have incorporated the shocks in the capital market of China as evident by Figure 2 .

The model best criteria have been applied in relation to the Shanghai stock exchange price indices on the basis of V-a-R @ 5\% by Model $1^{\text {st }}$ and Model $2^{\text {nd }}$. The resulted dispersion from model $1^{\text {st }}$ is less compared to the model $2^{\text {nd }}$ on the basis of composite year's analysis. The respective models' values are given as under;

$$
\begin{aligned}
& \Omega_{\mathrm{A}, \mathrm{SSE}}=4.0033 \\
& \Omega_{\mathrm{B}, \mathrm{SSE}}=4.0312
\end{aligned}
$$

Figure 2. Calculation of V-a-R on volatility of SSE through Log-GARCH and ARMA-GARCH model 1, 2 

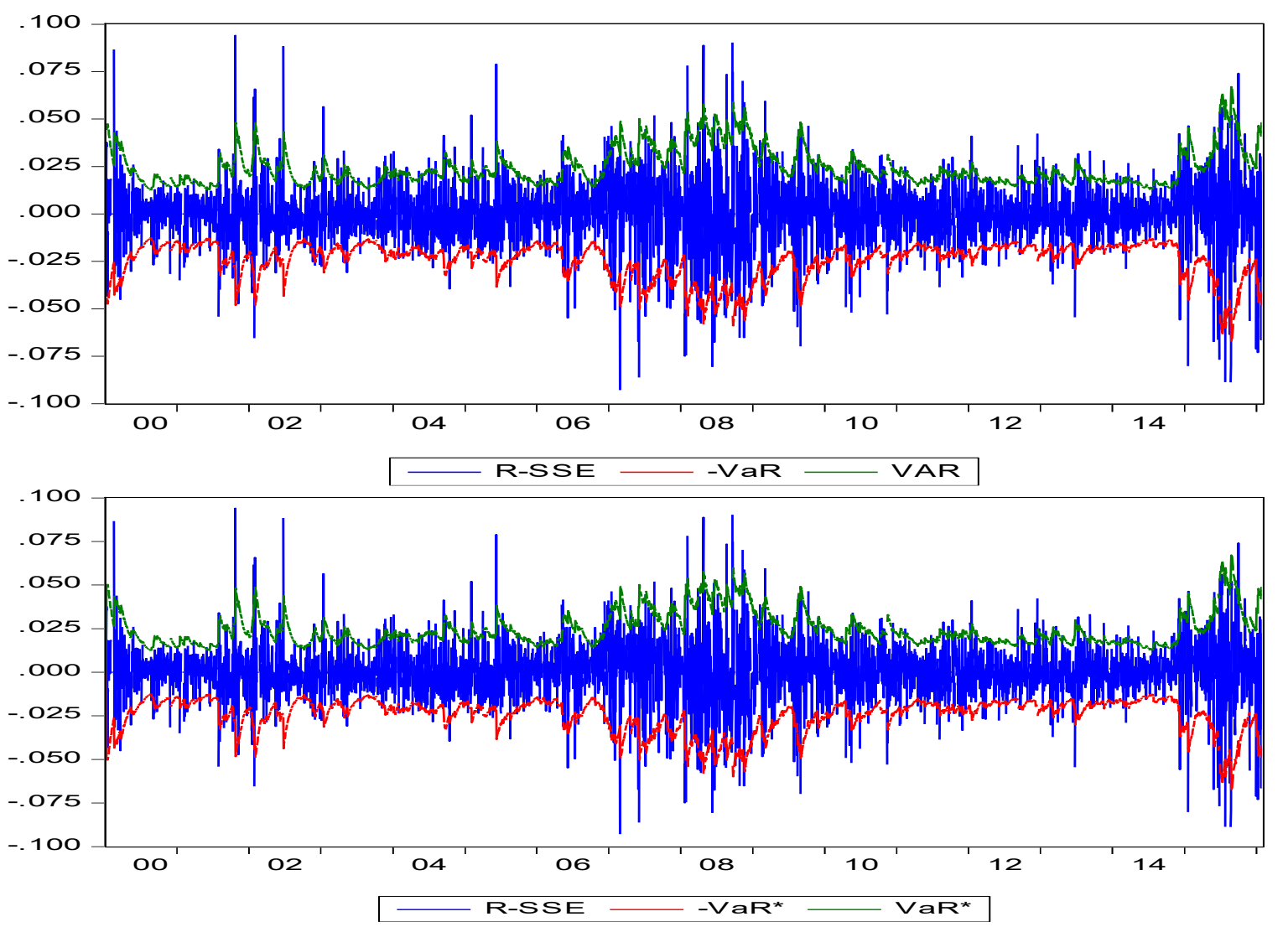

The evidence is given from the graph represents the Figure 3, which shows the model $1^{\text {st }}$ line is above the model $2^{\text {nd }}$ line on majority of the cases throughout the years.

Global proxy index analysis. Given graph below describes the relationship between the V-a-R and the returns of Yuan when incorporated the model 1 equation in assessing the magnitude of risk as per Figure 3.The bandwidth comprises of two independent series 1 and 2 i.e. $\mathrm{V}-\mathrm{a}-\mathrm{R}=-1.65 \sqrt{h} \mathrm{t}$ and $\mathrm{V}-\mathrm{a}-\mathrm{R}=1.65 \sqrt{h} \mathrm{t}$ respectively. The arrangement from the model 1 shows that the maximum loss with confidence level of 5\% over the composite period with respect to Yuan currency as a one of the global proxy indexes. Results evident from the year 2006 till 2009 showed the more volatility as compared to initial stage of the data. The maximum loss occurs at year 2005 is approximately -0.02 . It followed by the distress situation in the year 2015, which showed a panic situation in international markets with respect to currency in China market. The model 2 specifications have been arranged in order to apply V-a-R with the confidence level of $05 \%$ to evaluate the volatility in Yuan. The similarity existed with the model 1 and the bandwidth generated from the V-a-R statistics has incorporated composite period variation too.

Similarly, the V-a-R@05\% confidence level to assess the loss or deviations has been applied on the Oil prices, as an indicator of global proxy index. The arrangement from the model 1 has shown hint of volatility is highest throughout the composite period. There is also evidence that the V-a-R bandwidth approximately incorporated all the variations existed in this volatile industry. The maximum loss is upto -0.17 during the year 2001 , which is less than the existed volatility during the crisis of 2007-08. The model 2 arrangement has been shown in Figure 4, which shows that the association of $\mathrm{V}-\mathrm{a}-\mathrm{R}$ bandwidth and that of the variance of Oil prices is significantly close.

The last indicator in the global proxy index is the Gold prices and its significant has been evaluated against the respected model's arrangements with V-a-R bandwidth. The bandwidth margin comprises of values of two independent series i.e. $-1.65 \sqrt{h}$ and $1.65 \sqrt{h}$, respectively. The model 1 arrangement has been based upon the $\log$-GARCH $(1,1)$ specifications in relations to assess the volatility in gold prices against the respective indicators of global proxy index and 
Figure 3 Calculation of V-a-R on volatility of Yuan through Log-GARCH and ARMA-GARCH model 1, 2
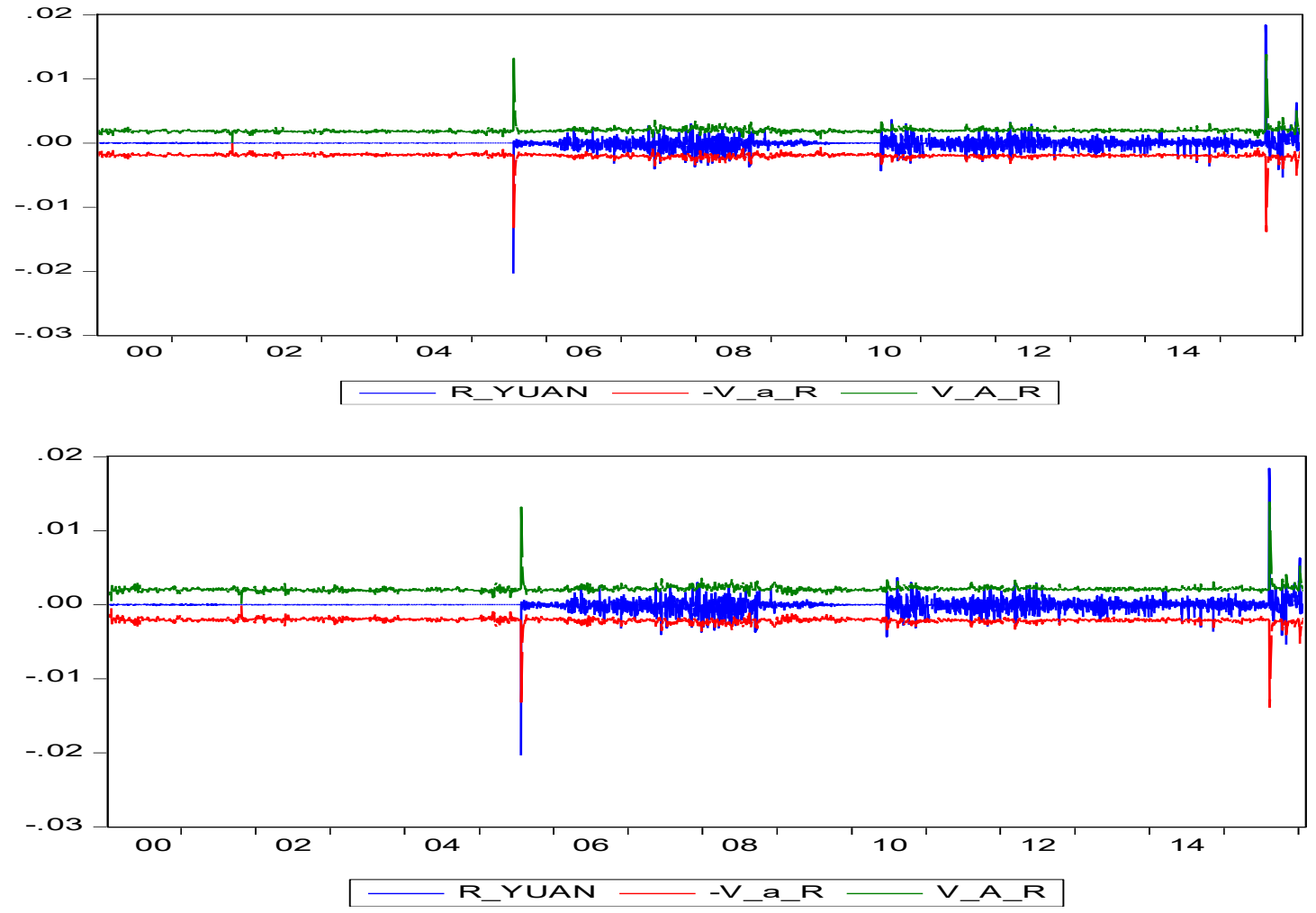

Figure 4. Calculation of V-a-R on volatility of Oil through Log-GARCH and ARMA-GARCH model 1, 2
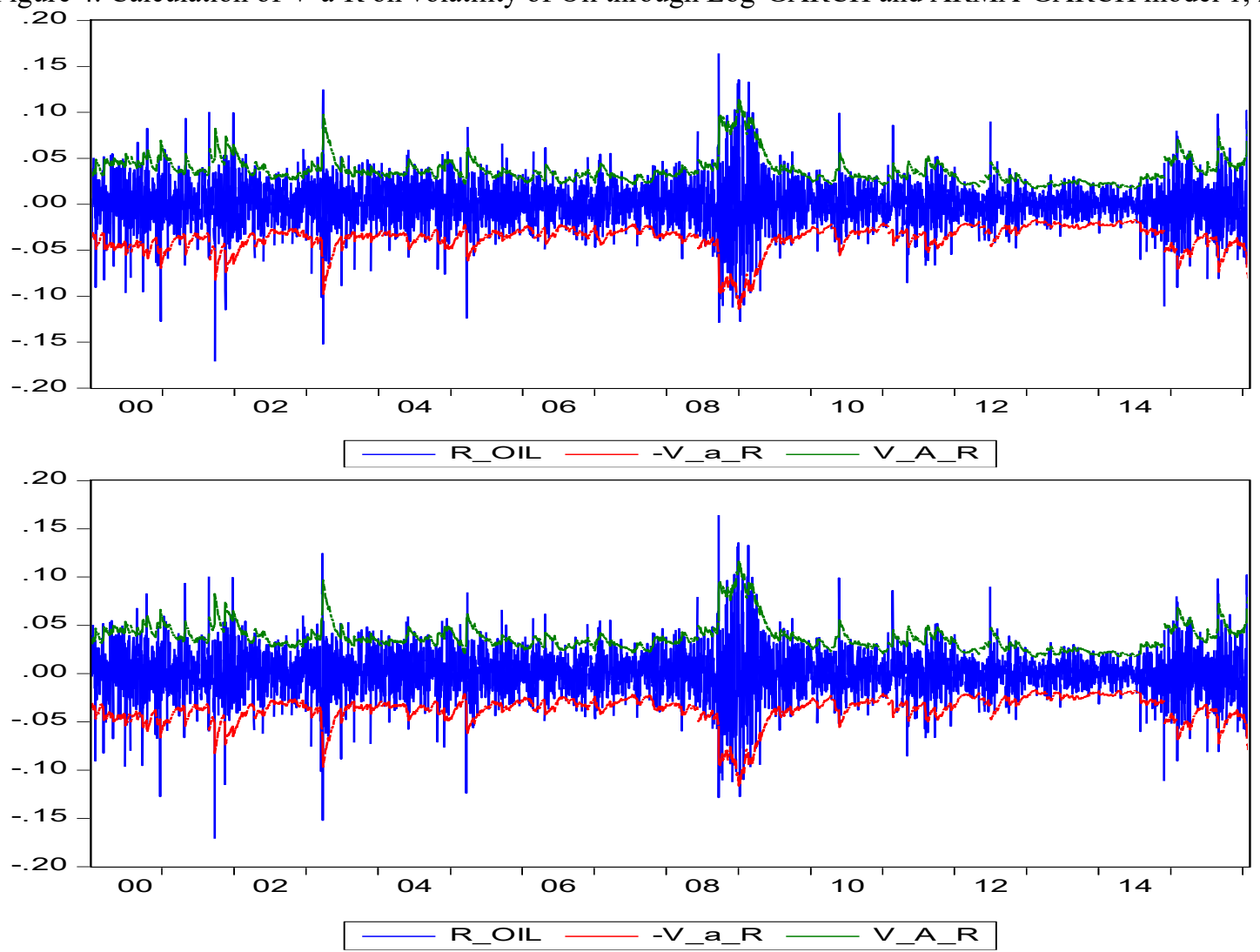

Volatility, Global Proxy Index, V-A-R: Empirical Study on Pakistan and China Stock (Muhammad Arslan) 
the stock exchanges. The maximum loss reported is during the year 2013 which is approximately 0.097. There found to be the close association among the volatility and the bandwidth proposed through V-a-R@5\%. Similarly, the model 2 specifications based on the arrangement which incorporates the volatility exist in the gold prices as last indicator of global proxy index has been presented in the Figure 4 . There also found to be the close association among the respective variations in the returns of the gold price and proposed bandwidth of V-a-R @ 5\% level of loss assessment.

The model best criteria have been applied in relation to the global proxy index on the basis of V-a-R @ 5\% by Model $1^{\text {st }}$ and Model $2^{\text {nd }}$. The resulted dispersion from model $1^{\text {st }}$ is less compared to the model $2^{\text {nd }}$ on the basis of composite year's analysis in case of all three indicators i.e. Yuan, Oil and Gold prices returns. The graph represents by the Figure 5 displays the results in confirmation to the Model $1^{\text {st }}$ as a best fitted model.

\section{CONCLUSION}

Value at risk approach handles market volatility at best that relates to its usage under certain conditions. The Risk has been most fundamental notion for experts and analysts in assessing their investment opportunities with specific to stock markets volatility. This study has incorporated filtered historical simulation for stock exchanges in order to access volatility condition based on V-a-R criteria. The findings reveals that $\log -\mathrm{GARCH}(1,1)$ model best explain the existing volatility in Shanghai stock exchange and dictates that the majority of the global proxy indicators shows their significant association in defining the volatility in said stock exchange. Due to weak statistical impact of these indicators on Pakistan stock exchange ARMA-GARCH $(1,1)$ is the best model to explain volatility in the said Stock Exchange. V-a-R has confirmed this @ 5\% confidence interval that the model first as shown less dispersion against the existing returns of price Indexes from respective stock exchanges. Since, the filtered historical simulation is the best method to assess betterly the risk from the historical data and incorporate the volatility, it is suggested that for future prospect the use of other statistical models should be used with the aim of assessing the loss as an outcome of risk through the other applications such as modified V-a-R and Sharpe ratios etc. Also, the study results are not driven by political-level risks and thus independent study can be conducted to evaluate the detrimental consequences of it on investment efficiency in such volatile stock exchanges.

\section{REFERENCES}

[1] Piroozfar, G. (2009). Forecasting Value at Risk with Historical and Filtered Historical Simulation Methods. UUDM Project Report.

[2] Korner, K.F., Kneafsey, K.P., \& Claessens. (1995). Forecasting volatility in commodity markets. Journal of Forecasting, 77-95.

[3] Mark R. Manfredo and Raymond M. Leuthold. (1998). Agricultural Applications of Value-at-Risk Analysis: A Perspective. OFOR, 98-104.

[4] Bank, D. (2013). Annual Report. DZ BANK Group.

[5] E. F. Fama and G. W. Schwert, "Asset returns and inflation," J. financ. econ., vol. 5, no. 2, pp. 115146, Nov. 1977.

[6] Jorion, P. (2007). Value at risk: the new benchmark for managing financial risk. Newyark : John Wiley $\&$ Sons.

[7] Angelidis, T. D. (2005). Modeling Rist for long and short term trading positions. The journal of Risk Management, 226-238.

[8] Engle, R. F. (1982). Autoregressive Conditional Heteroscedasticity with Estimation of the Vaiance of United Kingdom Inflation. Econometrica, 987-1008.

[9] J. S. Butler \& Barry Schachter. (1997). Estimating Value-at-Risk with a Precision measure by Combining kernel Estimation with Historical Simulation. 1-24.

[10] Black, F. (1976). Studies of Stock Price Volatility Changes. Journal of Business and economics, 177181.

[11] Angabini, A. W. (2011). GARCH Models and the Financial-Crsis-A study of the Malaysian Stock Market. The international Journal of Applied Economics and Finance, 226-236.

[12] Christoffersen, P. (2006). Value-at-Risk Models. journal of finance, 1-14.

[13] J. E. Cavanaugh, "Unifying the derivations for the Akaike and corrected Akaike information criteria," Stat. Probab. Lett., vol. 33, no. 2, pp. 201-208, Apr. 1997. 
[14] Badík, P. (2005).use of the method for measuring market risks and calculating capital aadequacy. NARODA BANKA SLOVENSKA, 17-21.

[15] Barone-Adesi, G., \& Giannopoulos, K. (2001). Non parametric V-a-R techniques. myths and realities. economnic notes, 167-181.

[16] Beder, T. S. (1994). V-a-R: Seductive but Dangerous. Financial analyst journal, 12-26.

[17] Bollerslev, T. (1986). Generalized Autoregressive Conditional Heteroskedasticity. Journal of Econometrics, 307-327.

[18] Engle, R. (2001). The use of ARCH/GARCH models in applied econometrics. . The Journal of Economic Perspectives, 157-168.

[19] G.Cera, E. Cera, and Gerdi Lito. (2013). A GARCH Model approach to Calculate the Value at Risk of Albanian LEK Exchange rate. European Scientific journal, 250-260.

[20] Helmut Mausserand Dan Rosen. (1999). Beyound V-a-R: From Measuring To Managing Risk. In Computational intelligence for financial Engineering , 163-178.

[21] Hendricks, D. (1996). Evaluation of Value-at-Risk Models Using Historical Data. Economic Policy Review Federal Reserve Bank of New York, 39-67. 